\title{
Role of the LKB1/AMPK pathway in tumor invasion and metastasis of cancer cells (Review)
}

\author{
NIANSHUANG LI*, DEQIANG HUANG ${ }^{*}$, NONGHUA LU and LINGYU LUO \\ Research Institute of Digestive Diseases, The First Affiliated Hospital of Nanchang University, \\ Nanchang, Jiangxi 330006, P.R. China
}

Received June 10, 2015; Accepted July 31, 2015

DOI: 10.3892/or.2015.4288

\begin{abstract}
Liver kinase B1 (LKB1), also known as serine/threonine kinase 11 (STK11), is a tumor suppressor that is inactivated in Peutz-Jeghers familial cancer syndrome. LKB1 phosphorylates and activates AMP-activated protein kinase (AMPK), which negatively regulates cancer cell proliferation and metabolism. However, recent evidence demonstrates that the LKB1/AMPK pathway is involved in the process of tumor invasion and migration, which is an important hallmark of carcinoma progression to higher pathological grades of malignancy. This review focuses on the function of the LKB1/AMPK pathway in the invasion and migration of cancer cells and provides an overview of therapeutic strategies aimed at this pathway in malignant tumors.
\end{abstract}

\section{Contents}

1. The function of liver kinase B1

2. The function of AMPK

3. Signal transduction in tumor invasion and metastasis

4. Regulation of tumor cell invasion and migration by LKB1/ AMPK signaling

5. Conclusions

\section{The function of liver kinase $B 1$}

Liver kinase B1 (LKB1), also named serine/threonine kinase 11 (STK11), was first identified in Peutz-Jeghers syndrome (PJS), which is a tumor susceptible syndrome

Correspondence to: Dr Lingyu Luo, Research Institute of Digestive Diseases, The First Affiliated Hospital of Nanchang University, 17 Yongwaizen Street, Nanchang, Jiangxi 330006, P.R. China E-mail: 15270855639@163.com

*Contributed equally

Key words: liver kinase B1, AMP-activated protein kinase, TGF- $\beta$ signal transduction, tumor invasion, metastasis characterized by inactivation of LKB1 $(1,2)$. Somatic mutations of LKB1 have also been found in many malignant tumors such as lung cancer (3), breast cancer (4) and colon cancer (5). When forming a complex with STE20-related adaptor protein (STRAD), LKB1 translocates from the nucleus to the cytoplasm to exert biological functions (6). Mouse protein-25 (MO25), a scaffold protein, interacts with the carboxyl terminus of STRAD and stabilizes the LKB1STRAD complex, leading to LKB1 activation (7).

It is well known that LKB1 controls cell polarity and maintains intracellular energy balance $(8,9)$. LKB1 functions as a tumor suppressor by phosphorylating and activating AMP-activated protein kinase (AMPK) $(8,9)$. LKB1/AMPK signaling regulates the formation of cytoskeletal microtubules and the expression of cell polarity proteins, including prostate apoptosis response-4 (PAR-4), to maintain cell polarity (10). LKB1 deficiency disturbs the polarity of mammary epithelial cells, resulting in cell disorder and an increased invasion and migration ability of epithelial cells (11). Moreover, LKB1 inhibits tumor initiation and progression by arresting the cell cycle in the G1 phase and by promoting cell apoptosis $(12,13)$. Therefore, dysregulation of LKB1 is not only the underlying pathological cause of PJS, but it is also related to the initiation and progression of various types of tumors via multiple mechanisms (Fig. 1).

\section{The function of AMPK}

AMPK is a heterotrimer formed by a catalytic subunit $(\alpha)$ and two regulatory subunits ( $\beta$ and $\gamma$ ) (14). AMPK can be phosphorylated and activated by LKB1 and calcium dependent protein kinase kinase- $\beta$ (CaMKK- $\beta$ ) (14-16). AMPK can also be activated by small molecules, including 5-aminoimidazole-4carboxamide-1- $\beta$-D-ribofuranoside (AICAR), metformin and analogues of these proteins $(17,18)$.

AMPK is a tumor suppressor and sensor of cellular energy status. It plays an important role in the control of cellular metabolism, proliferation and autophagy (19). As an energy sensor, AMPK is activated when the intracellular AMP/ATP ratio rises. Activated AMPK increases the production of ATP and decreases AMP consumption to maintain the balance of the AMP/ATP ratio (20). Rapidly growing cancer cells depend on a sustained energy supply. Tumor cells synthesize ATP by increasing glucose uptake and glycolysis to satisfy metabolic 


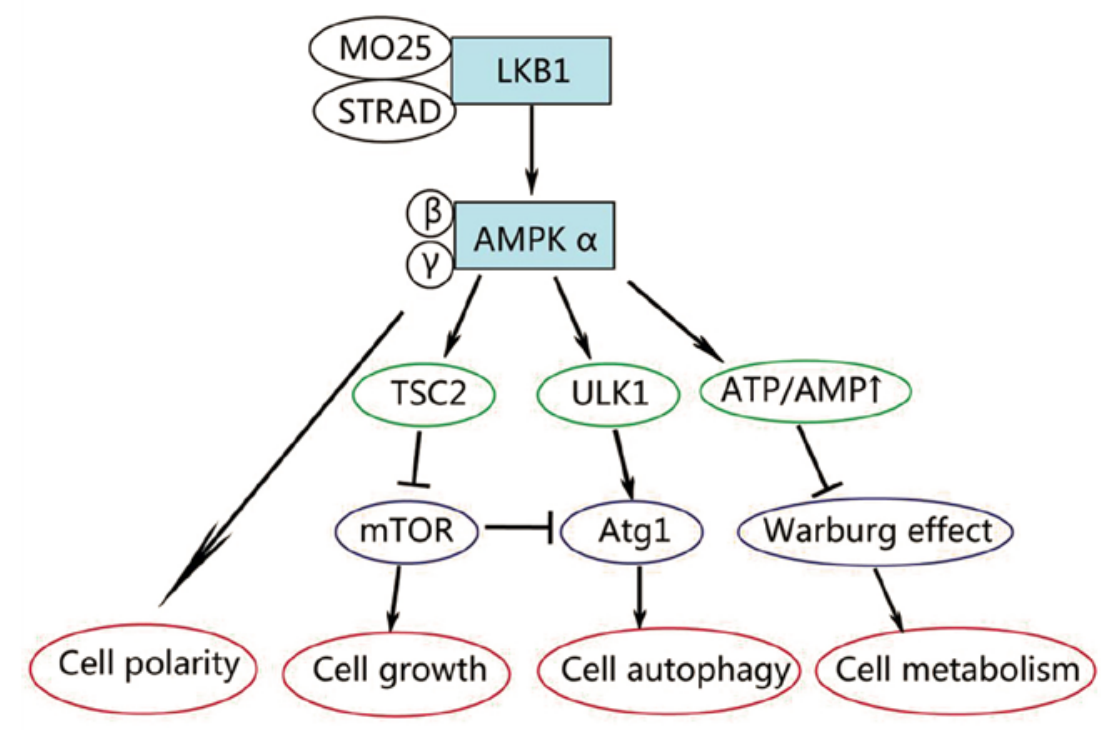

Figure 1. Regulation of cell growth, metabolism and polarity by LKB1/AMPK signaling. MO25 and STRAD form a complex with and activate LKB1, a major upstream kinase of AMPK. AMPK maintains cell polarity and suppresses cell growth and metabolism by negatively regulating the mTOR pathway and Warburg effect. Moreover, AMPK forms a complex with ULK1, leading to initiation of autophagy.

requirements, a phenomenon called the Warburg effect (21). It has been reported that AMPK suppresses the Warburg effect in tumor cells to inhibit tumor energy metabolism (22). Furthermore, dysregulation of AMPK is closely related to tumor growth, neovascularization, invasion and migration of cancer cells (23).

Rattan et al reported that AICAR increases protein expression of cyclin-dependent kinase inhibitor 1A (p21), cyclin-dependent kinase inhibitor $1 \mathrm{~B}$ (p27) and p53 via AMPK activation to suppress cell proliferation in various tumor types (24). In addition, in higher eukaryotes, AMPK directly phosphorylates serine-1387 in tumor suppressor tuberous sclerosis 2 (TSC2) to suppress the mammalian target of rapamycin (mTOR) signaling pathway (25). mTOR is a critical regulator of cell growth and autophagy (26). Autophagy involves degradation of damaged organelles and cytoplasmic components to provide materials and energy for cell survival under stressful conditions, such as starvation (27). mTOR inhibits autophagy through phosphorylating unc-51 like autophagy activating kinase 1 and 2 (ULK1 and ULK2). Stressful conditions, including starvation, hypoxia and energy depletion, lead to suppression of mTOR signaling, which in turn results in activation of autophagy (Fig. 1). Various studies have shown that AMPK stimulates ULK phosphorylation via inhibition of mTOR signaling to promote autophagy (28). Moreover, AMPK can also directly phosphorylate serine-555, threonine-574 and serine-637 on ULK1 to induce mitochondrial autophagy (mitophagy) (29).

\section{Signal transduction in tumor invasion and metastasis}

Metastasis is the leading cause of morbidity and mortality in patients diagnosed with cancer. In order to acquire metastatic characteristics, cancer cells must go through several stages including epithelial-mesenchymal transition (EMT) (30), degradation of the extracellular matrix (ECM) (31) and angio- genesis (32). At the molecular level, the invasion and migration of tumor cells may cause changes in gene expression such as matrix metalloproteinase-2 (MMP-2) (33), MMP-9 (34), $\alpha$-smooth muscle actin ( $\alpha$-SMA) (35), and EMT-associated proteins (36).

Recent studies have shown that alterations in signal transduction are hallmarks of tumor progression, which lead to uncontrolled cellular proliferation, invasion and metastasis. EMT is an important process in carcinogenesis by which epithelial cells lose their cell polarity and cell-cell adhesion, and acquire mesenchymal-like properties. The completion of EMT enhances cell motility, migratory capacity and ECM degradation ability, which promotes tumor cell invasion and migration $(37,38)$. The TGF- $\beta$ signaling pathway plays a crucial role in EMT (39). TGF- $\beta$-activated-R-Smad complex translocates from the cytoplasm to the nucleus (40), binds to the promoter of SNAIL1/2, ZEB1/2, triggers EMT and leads to the occurrence of tumor development, invasion and metastasis $(41,42)$. Wiercinska et al reported that TGF- $\beta$ upregulates the expression of MMP-2 and MMP-9 and induces breast cancer cell invasion via a Smad3- and Smad4-dependent manner (43).

TGF- $\beta$ also promotes cancer cell invasion and migration through non-Smad signaling pathways (Fig. 2). In NMUMG cell lines, the activation of mTOR signaling by TGF- $\beta$ occurs through activation of phosphatidylinositol 3-kinase (PI3K), protein kinase $\mathrm{B}(\mathrm{Akt})$, ribosomal protein $\mathrm{S} 6$ kinase 1 (S6K1) and eukaryotic initiation factor 4E-binding protein 1 (4EBP1) to induce EMT and cell invasion (44). Likewise, in carcinoma cells, TGF- $\beta$ regulates EMT-associated cytoskeletal changes and protein expression by activating mTOR complex 2 (mTOR2), further inducing EMT and cell invasion (45). Thakur et al demonstrated that TGF- $\beta$ upregulates the expression of Snail1 and increases the motility and invasiveness of human prostate cancer cells by activating the TRAF6/p38MAPK pathway (46). 


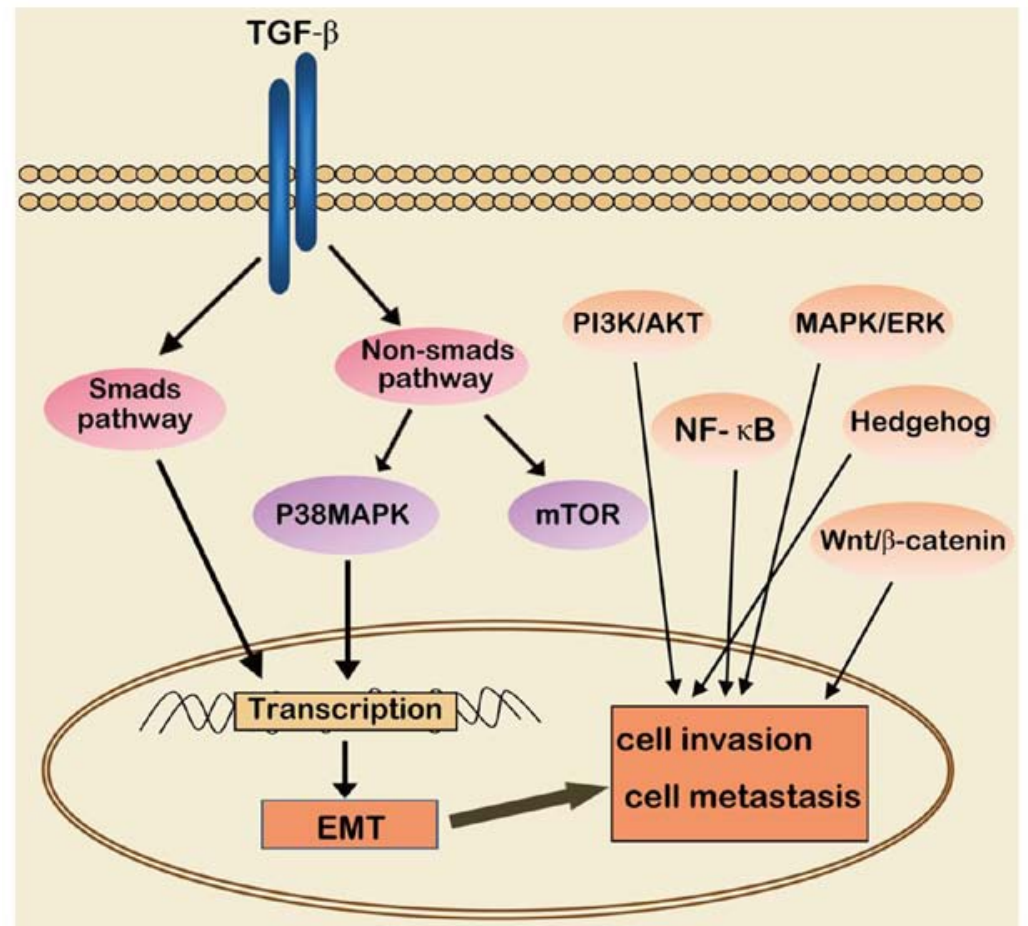

Figure 2. Multiple signaling pathways involved in cancer cell invasion and metastasis. TGF- $\beta$ induces EMT, invasion and metastasis of cancer cells via Smad and non-Smad pathways. In addition, the PI3K/AKT, NF-אB, Hedgehog, MAPK/ERK, p38MAPK, Wnt/ $\beta$-catenin signaling pathways are involved in tumor invasion and metastasis.

Apart from TGF- $\beta$ signaling, other signal pathways including PI3K/AKT (47), NF- $\mathrm{B}(48,49)$, Hedgehog $(50)$, MAPK/ERK (51), p38MAPK (52) and Wnt/3-catenin $(53,54)$ play important roles in tumor progression (Fig. 2). Wu et al identified a novel binding site (-626/-617) of NF-кB II in the promoter region of MMP-9 (55). It has been reported that treatment with Hedgehog inhibitors contributed to the motility and invasiveness of rhabdomyosarcoma cell lines (56).

\section{Regulation of tumor cell invasion and migration by LKB1/AMPK signaling}

The function of LKB1/AMPK in cancer cell invasion and migration. LKB1 is a well-known tumor suppressor and also an upstream kinase of tumor energy metabolism sensor AMPK. SNAIL, an EMT transcriptional factor, is upregulated in LKB1-deficient tumor cells (57). Similarly, in immortalized epithelial cells and lung adenocarcinoma cells depleted of LKB1, ZEB1 was found to be upregulated, accompanied by increased expression of mesenchymal marker proteins, cell viability and invasiveness (58). Double knockout of LKB1 and phosphatase and tensin homolog deleted in chromosome ten (PTEN) in mouse bladder tissues was found to lead to enhanced cell proliferation and tumor initiation, EMT, upregulation of SNAIL, nuclear localization of vimentin, and decreased expression of E-cadherin and tight junction protein zonal occludin-1 (ZO-1) (59). These data indicate that LKB1 plays a key role in the suppression of EMT during tumor progression.

AMPK, a conserved downstream kinase of LKB1, not only inhibits tumor cell proliferation and energy metabolism but also exerts dual regulatory effects on cancer cell invasion. Some studies have proposed that AMPK induces cell migration. Lysophophatidic acid (LPA) can induce the activation of AMPK and promote ovarian cancer metastasis (60). Park et al reported that silencing of AMPK abrogated the ability of anthocyanins to inhibit the migratory phenotype of hepatocarcinoma cells. However, more recent studies underscore the ability of AMPK to negatively regulate tumor growth and invasion. Metformin, an AMPK activator, was reported to inhibit EMT and melanoma metastasis in an AMPK/ p53-dependent manner (61). Similarly, metformin was found to inhibit MMP-2 and MMP-9 levels, cell proliferation and migration of human umbilical vein endothelial cells (62). Chemokine ligand 3 (CCL-3) can promote MMP-2 expression and the migration of human chondrosarcoma cells, which is abolished by AMPK activation (63). Kim et al reported that berberine dramatically increased AMPK phosphorylation but decreased ERK activity and cytochrome $c$ oxidase subunit II (COX-2) expression, leading to suppression of human melanoma cell migration (64). These studies suggest that AMPK plays an important role in tumor invasion and migration.

The LKB1/AMPK pathway regulates cancer cell invasion and migration via a variety of signaling pathways. Tumor cell invasion and metastasis is a complex process that results from interaction and crosstalk between multiple pathways. The LKB1/AMPK pathway regulates invasion and metastasis via diversified signaling pathways, such as NF- $\kappa \mathrm{B}, \mathrm{AKT}$, forkhead box O3 (Foxo3a), TGF- $\beta$ and mTOR. It has been reported that AICAR activates AMPK to suppress AKT/ FOXO3 signaling, inhibiting EMT and reversing mesen- 
chymal characteristics of tumor cells (65). In PC3 and PC3M cells, AICAR and A769662 downregulated mTOR and S6K1 levels, and inhibited migration by activating AMPK (66). Emerging evidence indicates that LKB1/AMPK inhibits tumor invasion and migration through downregulation of the downstream factors of TGF- $\beta$ signaling, such as MMPs and Snail $(67,68)$. It was reported that AMPK inhibited TGF- $\beta$-induced EMT in HK-2 cells (69). In addition, AICAR, metformin and adiponectin were found to activate AMPK, but inhibited TGF- $\beta$-induced fibrosis via downregulation of collagen type I $\alpha 1$ (COL1A) and $\alpha$-SMA expression in hepatic stellate cells (70). AMPK-mediated proteasomal degradation of p300 is the underlying mechanism of activation (70). Moreover, treatment of breast cancer cells with metformin decreased the functions of TGF- $\beta$ (71). Conversely, silencing an AMPK downstream effector, lipopolysaccharide-induced TNF- $\alpha$ factor (LITAF), by RNA interference, accelerated tumor growth (72). Furthermore, metformin was shown to arrest cell cycle progression, inhibit proliferation and induce apoptosis of breast cancer cells through suppression of AKT and ERK signaling pathways (73). In contrast, inhibition of AMPK resulted in enhanced cell proliferation and migration of prostate cancer cells, accompanied by an upregulation of S6K1 and insulin-like growth factor 1 (IGF-1) and downregulation of p53 and p21 (74).

AMPK can also indirectly modulate tumor progression through various other signaling pathways.Capsaicin suppressed the invasion and migration of cholangiocarcinoma cells by inhibiting the AMPK-NF- $\mathrm{KB}$ pathway, leading to subsequent reduced expression of MMP-9 (75). AMPK/JAK/STATA3 and AMPK/GSK3 $\beta / \beta$-catenin pathways were found to be involved in hepatocarcinoma cell and endometrial cancer cell invasion and metastasis $(76,77)$. Novel (nua) kinase family 1 (NUAK1) and ARK5, members of the AMPK family, play important roles in cancer cell migration and invasion by regulating the $\mathrm{AKT}$ and NF- $\mathrm{KB}$ signaling pathways $(78,79)$.

\section{Conclusions}

LKB1, an upstream kinase of AMPK, is a tumor suppressor. LKB1/AMPK maintains cell polarity and inhibits cell proliferation and energy metabolism. Moreover, recent studies demonstrated that the LKB1/AMPK pathway plays an important role in the invasion and migration of tumor cells by regulating gene expression and activation of multiple signaling pathways. The TGF- $\beta$ signaling pathway promotes cancer metastasis while the LKB1/AMPK pathway negatively regulates the progression of cancer. Thus, the regulation of TGF- $\beta$ signaling may be an important mechanism by which LKB1/AMPK inhibits tumor metastasis. Further investigation of the crosstalk between the LKB1/AMPK pathway and other signaling pathways will accelerate the development and approval of highly targeted cancer drugs.

\section{Acknowledgements}

This study was supported by the National Natural Science Foundation of China (nos. 8117195, 81272926, 31460304 and 81460374) and Jiangxi Provincial Department of Health (nos. 20155117 and 20155145). We would like to thank Dr Zhijun
Luo (School of Medicine, Boston University) for the kind assistance with the present study.

\section{References}

1. Resta N, Pierannunzio D, Lenato GM, Stella A, Capocaccia R, Bagnulo R, Lastella P, Susca FC, Bozzao C, Loconte DC, et al: Cancer risk associated with STK11/LKB1 germline mutations in Peutz-Jeghers syndrome patients: Results of an Italian multicenter study. Dig Liver Dis 45: 606-611, 2013.

2. Chen CY, Zhang XM, Wang FY, Wang ZK, Zhu M, Ma GJ, Zhang YY, Jin XX, Shi H and Liu J: Mutation screening of LKB1 gene in familial Peutz-Jeghers syndrome patients. Zhonghua Yi Xue Yi Chuan Xue Za Zhi 29: 121-125, 2012 (In Chinese).

3. Fang R, Zheng C, Sun Y, Han X, Gao B, Li C, Liu H, Wong KK, Liu XY, Chen $\mathrm{H}$, et al: Integrative genomic analysis reveals a high frequency of LKB1 genetic alteration in Chinese lung adenocarcinomas. J Thorac Oncol 9: 254-258, 2014.

4. Loi S, Michiels S, Lambrechts D, Fumagalli D, Claes B, Kellokumpu-Lehtinen PL, Bono P, Kataja V, Piccart MJ, Joensuu H, et al: Somatic mutation profiling and associations with prognosis and trastuzumab benefit in early breast cancer. J Natl Cancer Inst 105: 960-967, 2013.

5. Avizienyte E, Roth S, Loukola A, Hemminki A, Lothe RA, Stenwig AE, Fosså SD, Salovaara R and Aaltonen LA: Somatic mutations in LKB1 are rare in sporadic colorectal and testicular tumors. Cancer Res 58: 2087-2090, 1998.

6. Veleva-Rotse BO, Smart JL, Baas AF, Edmonds B, Zhao ZM, Brown A, Klug LR, Hansen K, Reilly G, Gardner AP, et al: STRAD pseudokinases regulate axogenesis and LKB1 stability. Neural Dev 9: 5, 2014.

7. Zeqiraj E, Filippi BM, Deak M, Alessi DR and van Aalten DM: Structure of the LKB1-STRAD-MO25 complex reveals an allosteric mechanism of kinase activation. Science 326: 1707-1711, 2009.

8. Mirouse V, Swick LL, Kazgan N, St Johnston D and Brenman JE: LKB1 and AMPK maintain epithelial cell polarity under energetic stress. J Cell Biol 203: 373, 2013.

9. Dahmani R, Just PA, Delay A, Canal F, Finzi L, Prip-Buus C, Lambert M, Sujobert P, Buchet-Poyau K, Miller E, et al: A novel LKB1 isoform enhances AMPK metabolic activity and displays oncogenic properties. Oncogene 34: 2337-2346, 2015.

10. Partanen JI, Tervonen TA and Klefström J: Breaking the epithelial polarity barrier in cancer: The strange case of LKB1/PAR-4. Philos Trans R Soc Lond B Biol Sci 368: 20130111, 2013.

11. Li J, Liu J, Li P, Mao X, Li W, Yang J and Liu P: Loss of LKB1 disrupts breast epithelial cell polarity and promotes breast cancer metastasis and invasion. J Exp Clin Cancer Res 33: 70, 2014.

12. Liang X, Wang P, Gao Q and Tao X: Exogenous activation of LKB1/AMPK signaling induces G1 arrest in cells with endogenous LKB1 expression. Mol Med Rep 9: 1019-1024, 2014.

13. Luo L, Huang W, Tao R, Hu N, Xiao ZX and Luo Z: ATM and LKB1 dependent activation of AMPK sensitizes cancer cells to etoposide-induced apoptosis. Cancer Lett 328: 114-119, 2013.

14. Hardie DG and Alessi DR: LKB1 and AMPK and the cancer-metabolism link - ten years after. BMC Biol 11: 36, 2013.

15. Gormand A, Henriksson E, Ström K, Jensen TE, Sakamoto K and Göransson O: Regulation of AMP-activated protein kinase by LKB1 and CaMKK in adipocytes. J Cell Biochem 112: 1364-1375, 2011.

16. Hardie DG: The LKB1-AMPK pathway-friend or foe in cancer? Cancer Cell 23: 131-132, 2013.

17. Hardie DG, Ross FA and Hawley SA: AMP-activated protein kinase: A target for drugs both ancient and modern. Chem Biol 19: 1222-1236, 2012.

18. Rena G, Pearson ER and Sakamoto K: Molecular mechanism of action of metformin: Old or new insights? Diabetologia 56: 1898-1906, 2013.

19. Mihaylova MM and Shaw RJ: The AMPK signalling pathway coordinates cell growth, autophagy and metabolism. Nat Cell Biol 13: 1016-1023, 2011.

20. Carling D, MayerFV, Sanders MJ and Gamblin SJ: AMP-activated protein kinase: Nature's energy sensor. Nat Chem Biol 7: 512-518, 2011.

21. Lu J, Tan M and Cai Q: The Warburg effect in tumor progression: Mitochondrial oxidative metabolism as an anti-metastasis mechanism. Cancer Lett 356: 156-164, 2015. 
22. Faubert B, Boily G, Izreig S, Griss T, Samborska B, Dong Z, Dupuy F, Chambers C, Fuerth BJ, Viollet B, et al: AMPK is a negative regulator of the Warburg effect and suppresses tumor growth in vivo. Cell Metab 17: 113-124, 2013.

23. Teng RJ, Du J, Afolayan AJ, Eis A, Shi Y and Konduri GG: AMP kinase activation improves angiogenesis in pulmonary artery endothelial cells with in utero pulmonary hypertension. Am J Physiol Lung Cell Mol Physiol 304: L29-L42, 2013.

24. Rattan R, Giri S, Singh AK and Singh I: 5-Aminoimidazole-4-carboxamide-1-beta-D-ribofuranoside inhibits cancer cell proliferation in vitro and in vivo via AMP-activated protein kinase. J Biol Chem 280: 39582-39593, 2005.

25. van Veelen W, Korsse SE, van de Laar L and Peppelenbosch MP: The long and winding road to rational treatment of cancer associated with LKB1/AMPK/TSC/mTORC1 signaling. Oncogene 30: 2289-2303, 2011.

26. Dunlop EA and Tee AR: mTOR and autophagy: A dynamic relationship governed by nutrients and energy. Semin Cell Dev Biol 36: 121-129, 2014.

27. Jung CH, Ro SH, Cao J, Otto NM and Kim DH: mTOR regulation of autophagy. FEBS Lett 584: 1287-1295, 2010.

28. Shang L and Wang X: AMPK and mTOR coordinate the regulation of Ulk1 and mammalian autophagy initiation. Autophagy 7: 924-926, 2011.

29. Mack HI,Zheng B, Asara JM and Thomas SM: AMPK-dependent phosphorylation of ULK1 regulates ATG9 localization. Autophagy 8: 1197-1214, 2012.

30. Fenouille N, Tichet M, Dufies M, Pottier A, Mogha A, Soo JK, Rocchi S, Mallavialle A, Galibert MD, Khammari A, et al: The epithelial-mesenchymal transition (EMT) regulatory factor SLUG (SNAI2) is a downstream target of SPARC and AKT in promoting melanoma cell invasion. PLoS One 7: e40378, 2012.

31. Wong GS and Rustgi AK: Matricellular proteins: Priming the tumour microenvironment for cancer development and metastasis. Br J Cancer 108: 755-761, 2013.

32. Xiang X, Zhao X, Qu H, Li D, Yang D, Pu J, Mei H, Zhao J, Huang K, Zheng L, et al: Hepatocyte nuclear factor 4 alpha promotes the invasion, metastasis and angiogenesis of neuroblastoma cells via targeting matrix metalloproteinase 14. Cancer Lett 359: 187-197, 2015.

33. Magee PJ, Allsopp P, Samaletdin A and Rowland IR: Daidzein $\mathrm{R}-(+)$ equol and S-(-)equol inhibit the invasion of MDA-MB-231 breast cancer cells potentially via the down-regulation of matrix metalloproteinase-2. Eur J Nutr 53: 345-350, 2014.

34. Merdad A, Karim S, Schulten HJ, Dallol A, Buhmeida A Al-Thubaity F, Gari MA, Chaudhary AG, Abuzenadah AM and Al-Qahtani MH: Expression of matrix metalloproteinases (MMPs) in primary human breast cancer: MMP-9 as a potential biomarker for cancer invasion and metastasis. Anticancer Res 34: $1355-1366,2014$

35. Jiang H, Gao M, Shen Z, Luo B, Li R, Jiang X, Ding R, Ha Y, Wang $Z$ and Jie W: Blocking PI3K/Akt signaling attenuates metastasis of nasopharyngeal carcinoma cells through induction of mesenchymal-epithelial reverting transition. Oncol Rep 32: 559-566, 2014.

36. Son $\mathrm{H}$ and Moon A: Epithelial-mesenchymal transition and cell invasion. Toxicol Res 26: 245-252, 2010.

37. Wang Y and Zhou BP: Epithelial-mesenchymal transition in breast cancer progression and metastasis. Chin J Cancer 30 603-611, 2011

38. May CD, Sphyris N, Evans KW, Werden SJ, Guo W and Mani SA Epithelial-mesenchymal transition and cancer stem cells: A dangerously dynamic duo in breast cancer progression. Breast Cancer Res 13: 202, 2011

39. Xu J, Lamouille S and Derynck R: TGF-beta-induced epithelial to mesenchymal transition. Cell Res 19: 156-172, 2009.

40. Weiss A and Attisano L: The TGFbeta superfamily signaling pathway. Wiley Interdiscip Rev Dev Biol 2: 47-63, 2013.

41. Katsuno Y, Lamouille S and Derynck R: TGF- $\beta$ signaling and epithelial-mesenchymal transition in cancer progression. Curr Opin Oncol 25: 76-84, 2013.

42. Porsch H, Bernert B, Mehić M, Theocharis AD, Heldin CH and Heldin P: Efficient TGF $\beta$-induced epithelial-mesenchymal transition depends on hyaluronan synthase HAS2. Oncogene 32 : $4355-4365,2013$

43. Wiercinska E, Naber HP, Pardali E, van der Pluijm G, van Dam H and ten Dijke P: The TGF- $\beta /$ Smad pathway induces breast cancer cell invasion through the up-regulation of matrix metalloproteinase 2 and 9 in a spheroid invasion model system. Breast Cancer Res Treat 128: 657-666, 2011
44. Lamouille S and Derynck R: Cell size and invasion in TGF-beta-induced epithelial to mesenchymal transition is regulated by activation of the mTOR pathway. J Cell Biol 178: 437-451, 2007

45. Lamouille S, Connolly E, Smyth JW, Akhurst RJ and Derynck R: TGF- $\beta$-induced activation of mTOR complex 2 drives epithelial-mesenchymal transition and cell invasion. J Cell Sci 125: 1259-1273, 2012.

46. Thakur N, Gudey SK, Marcusson A, Fu JY, Bergh A, Heldin CH and Landström M: TGF $\beta$-induced invasion of prostate cancer cells is promoted by c-Jun-dependent transcriptional activation of Snail1. Cell Cycle 13: 2400-2414, 2014.

47. Saini KS, Loi S, de Azambuja E, Metzger-Filho O, Saini ML, Ignatiadis M, Dancey JE and Piccart-Gebhart MJ: Targeting the PI3K/AKT/mTOR and Raf/MEK/ERK pathways in the treatment of breast cancer. Cancer Treat Rev 39: 935-946, 2013.

48. Yeh CB, Hsieh MJ, Hsieh YH, Chien MH, Chiou HL and Yang SF: Antimetastatic effects of norcantharidin on hepatocellular carcinoma by transcriptional inhibition of MMP-9 through modulation of NF- $\mathrm{BB}$ activity. PLoS One 7: e31055, 2012.

49. Zhang W, Liu Y and Wang CW: S100A4 promotes squamous cell laryngeal cancer Hep-2 cell invasion via NF- $\kappa$ B/MMP-9 signal. Eur Rev Med Pharmacol Sci 18: 1361-1367, 2014.

50. Lu JT, Zhao WD, He W and Wei W: Hedgehog signaling pathway mediates invasion and metastasis of hepatocellular carcinoma via ERK pathway. Acta Pharmacol Sin 33: 691-700, 2012.

51. Setia S, Nehru B and Sanyal SN: Upregulation of MAPK/Erk and PI3K/Akt pathways in ulcerative colitis-associated colon cancer. Biomed Pharmacother 68: 1023-1029, 2014.

52. Arechederra M, Priego N, Vázquez-Carballo A, Sequera C, Gutiérrez-Uzquiza Á, Cerezo-Guisado MI, Ortiz-Rivero S, Roncero C, Cuenda A, Guerrero C, et al: p38 MAPK down-regulates fibulin 3 expression through methylation of gene regulatory sequences: Role in migration and invasion. J Biol Chem 290: 4383-4397, 2015.

53. Chen X, Meng J, Yue W, Yu J, Yang J, Yao Z and Zhang L: Fibulin-3 suppresses Wnt/ $\beta$-catenin signaling and lung cancer invasion. Carcinogenesis 35: 1707-1716, 2014

54. Liu Z, Rebowe RE, Wang Z, Li Y, Wang Z, DePaolo JS, Guo J, Qian C and Liu W: KIF3a promotes proliferation and invasion via Wnt signaling in advanced prostate cancer. Mol Cancer Res 12: 491-503, 2014

55. Wu HT, Sie SS, Kuan TC and Lin CS: Identifying the regulative role of NF- $\kappa \mathrm{B}$ binding sites within promoter region of human matrix metalloproteinase 9 (mmp-9) by TNF- $\alpha$ induction. Appl Biochem Biotechnol 169: 438-449, 2013.

56. Oue T, Uehara S, Yamanaka H, Nomura M and Usui N: Hedgehog signal inhibitors suppress the invasion of human rhabdomyosarcoma cells. Pediatr Surg Int 29: 1153-1158, 2013.

57. Goodwin JM, Svensson RU, Lou HJ, Winslow MM, Turk BE and Shaw RJ: An AMPK-independent signaling pathway downstream of the LKB1 tumor suppressor controls Snaill and metastatic potential. Mol Cell 55: 436-450, 2014.

58. Roy BC, Kohno T, Iwakawa R, Moriguchi T, Kiyono T, Morishita K, Sanchez-Cespedes M, Akiyama T and Yokota J: Involvement of LKB1 in epithelial-mesenchymal transition (EMT) of human lung cancer cells. Lung Cancer 70: 136-145, 2010.

59. Shorning BY, Griffiths D and Clarke AR: Lkb1 and Pten synergise to suppress mTOR-mediated tumorigenesis and epithelial-mesenchymal transition in the mouse bladder. PLoS One 6: e16209, 2011.

60. Kim EK, Park JM, Lim S, Choi JW, Kim HS, Seok H, Seo JK, Oh K, Lee DS, Kim KT, et al: Activation of AMP-activated protein kinase is essential for lysophosphatidic acid-induced cell migration in ovarian cancer cells. J Biol Chem 286: 24036-24045, 2011.

61. Cerezo M, Tichet M, Abbe P, Ohanna M, Lehraiki A, Rouaud F, Allegra M, Giacchero D, Bahadoran P, Bertolotto C, et al: Metformin blocks melanoma invasion and metastasis development in AMPK/p53-dependent manner. Mol Cancer Ther 12: 1605-1615, 2013.

62. Esfahanian N, Shakiba Y, Nikbin B, Soraya H, Maleki-Dizaji N, Ghazi-Khansari $\mathrm{M}$ and Garjani A: Effect of metformin on the proliferation, migration, and MMP-2 and -9 expression of human umbilical vein endothelial cells. Mol Med Rep 5: 1068-1074, 2012. 
63. Hsu CJ, Wu MH, Chen CY, Tsai CH, Hsu HC and Tang $\mathrm{CH}$ : AMP-activated protein kinase activation mediates CCL3-induced cell migration and matrix metalloproteinase- 2 expression in human chondrosarcoma. Cell Commun Signal 11: 68, 2013.

64. Kim HS, Kim MJ, Kim EJ, Yang Y, Lee MS and Lim JS: Berberine-induced AMPK activation inhibits the metastatic potential of melanoma cells via reduction of ERK activity and COX-2 protein expression. Biochem Pharmacol 83: 385-394, 2012.

65. Chou CC, Lee KH, Lai IL, Wang D, Mo X, Kulp SK, Shapiro CL and Chen CS: AMPK reverses the mesenchymal phenotype of cancer cells by targeting the Akt-MDM2-Foxo3a signaling axis Cancer Res 74: 4783-4795, 2014.

66. Choudhury Y, Yang Z, Ahmad I, Nixon C, Salt IP and Leung HY: AMP-activated protein kinase (AMPK) as a potential therapeutic target independent of PI3K/Akt signaling in prostate cancer. Oncoscience 1: 446-456, 2014.

67. Petursson F, Husa M, June R, Lotz M, Terkeltaub R and Liu-Bryan R: Linked decreases in liver kinase B1 and AMP-activated protein kinase activity modulate matrix catabolic responses to biomechanical injury in chondrocytes. Arthritis Res Ther 15: R77, 2013.

68. Ramnanan CJ, McMullen DC, Groom AG and Storey KB: The regulation of AMPK signaling in a natural state of profound metabolic rate depression. Mol Cell Biochem 335: 91-105, 2010.

69. Lee JH, Kim JH, Kim JS, Chang JW, Kim SB, Park JS and Lee SK: AMP-activated protein kinase inhibits TGF- $\beta-$, angiotensin II-, aldosterone-, high glucose-, and albumin-induced epithelial-mesenchymal transition. Am J Physiol Renal Physiol 304: F686-F697, 2013.

70. Lim JY, Oh MA, Kim WH, Sohn HY and Park SI: AMP-activated protein kinase inhibits TGF- $\beta$-induced fibrogenic responses of hepatic stellate cells by targeting transcriptional coactivator p300. J Cell Physiol 227: 1081-1089, 2012.

71. Goncharova EA, Goncharov DA, James ML, AtochinaVasserman EN, Stepanova V, Hong SB, Li H, Gonzales L, Baba M, Linehan WM, et al: Folliculin controls lung alveolar enlargement and epithelial cell survival through E-cadherin, LKB1, and AMPK. Cell Reports 7: 412-423, 2014.
72. Zhou J, Yang Z, Tsuji T, Gong J, Xie J, Chen C, Li W, Amar S and Luo Z: LITAF and TNFSF15, two downstream targets of AMPK, exert inhibitory effects on tumor growth. Oncogene 30: 1892-1900, 2011

73. Queiroz EA, Puukila S, Eichler R, Sampaio SC, Forsyth HL, Lees SJ, Barbosa AM, Dekker RF, Fortes ZB and Khaper N: Metformin induces apoptosis and cell cycle arrest mediated by oxidative stress, AMPK and FOXO3a in MCF-7 breast cancer cells. PLoS One 9: e98207, 2014.

74. Zhou J, Huang W, Tao R, Ibaragi S, Lan F, Ido Y, Wu X, Alekseyev YO, Lenburg ME, Hu GF, et al: Inactivation of AMPK alters gene expression and promotes growth of prostate cancer cells. Oncogene 28: 1993-2002, 2009.

75. Lee GR, Jang SH, Kim CJ, Kim AR, Yoon DJ, Park NH and Han IS: Capsaicin suppresses the migration of cholangiocarcinoma cells by down-regulating matrix metalloproteinase-9 expression via the AMPK-NF- $\kappa$ B signaling pathway. Clin Exp Metastasis 31: 897-907, 2014

76. Wu X, Yan Q, Zhang Z, Du G and Wan X: Acrp30 inhibits leptin-induced metastasis by downregulating the JAK/STAT3 pathway via AMPK activation in aggressive SPEC-2 endometrial cancer cells. Oncol Rep 27: 1488-1496, 2012.

77. Park SY, Lee YK, Lee WS, Park OJ and Kim YM: The involvement of AMPK/GSK3-beta signals in the control of metastasis and proliferation in hepato-carcinoma cells treated with anthocyanins extracted from Korea wild berry Meoru. BMC Complement Altern Med 14: 109, 2014.

78. Suzuki A, Lu J, Kusakai G, Kishimoto A, Ogura T and Esumi H: ARK5 is a tumor invasion-associated factor downstream of Akt signaling. Mol Cell Biol 24: 3526-3535, 2004.

79. Chen P, Li K, Liang Y, Li L and Zhu X: High NUAK1 expression correlates with poor prognosis and involved in NSCLC cells migration and invasion. Exp Lung Res 39: 9-17, 2013. 